\title{
Stark widths and shifts of triply ionized argon spectral lines
}

\author{
S. Djeniže, S. Bukvić, and D. Mišković
}

Faculty of Physics, University of Belgrade, PO Box 368, 11000 Belgrade, Serbia, Yugoslavia

Received 9 June 2000 / Accepted 13 November 2000

\begin{abstract}
The Stark widths and shifts of 18 triply ionized argon (Ar IV) spectral lines have been measured at an electron density of $1.910^{23} \mathrm{~m}^{-3}$ and electron temperature of $22500 \mathrm{~K}$ in a linear pulsed-arc discharge-containing argon-helium mixture. The measured values were compared to the existing calculated and experimental data.
\end{abstract}

Key words. lines: profiles - atomic data - plasmas

\section{Introduction}

Knowledge of the characteristics of triply ionized argon (Ar IV) spectral lines is important for the determination of chemical abundances of elements and, also, for the estimation of the radiative transfer through stellar plasmas, as well as for opacity calculations (Inglesias et al. 1990; Zeippen 1995). A number of experimental and theoretical papers have dealt with the Stark broadening parameters of Ar IV spectral lines (Lesage \& Fuhr 1998 and references therein). Thus, the Stark width values of 12 spectral lines have been measured in four experiments (Platiša et al. 1975; Purić et al. 1988; Hey et al. 1990; Kobilarov \& Konjević 1990) performed at electron temperatures $(T)$ up to $110000 \mathrm{~K}$. On the other hand, only one experiment (Kobilarov \& Konjević 1990) deals with the Stark shift of 4 Ar IV spectral lines.

The aim of this work is to present measured Stark FWHM (full-width at half intensity maximum, $W$ ) and Stark shift (d) of $18 \mathrm{Ar}$ IV spectral lines at an electron temperature of $22500 \mathrm{~K}$ and an electron density $(N)$ of $1.910^{23} \mathrm{~m}^{-3}$ in two transitions $\left(4 \mathrm{~s}-4 \mathrm{p}\right.$ and $\left.4 \mathrm{~s}^{\prime}-4 \mathrm{p}^{\prime}\right)$ belonging to eight different multiplets. The discharge conditions were selected in order to establish a lower electron temperature. This is an area in which W strongly depends on the electron temperature and accurately measured W values can be used to select the most appropriate among various theoretical approximations (Griem 1974). Stark FWHM values for six lines are, for the first time, investigated in this work, such as values of Stark shifts of 13 spectral lines.

\section{Experiment}

A modified version of the linear low-pressure pulsed arc (Djeniže et al. 1991; 1998) has been used as a plasma

Send offprint requests to: S. Djeniže, e-mail: steva@ff.bg.ac.yu source. A pulsed discharge was driven in a quartz discharge tube of $5 \mathrm{~mm}$ inner diameter and effective plasma length of $7.2 \mathrm{~cm}$ (Fig. 1 in Djeniže et al. 1991; 1998). The tube has end-on quartz windows. On the opposite side of the electrodes, the glass tube was expanded in order to reduce erosion of the glass wall and sputtering, also, of the electrode material onto the quartz windows. The working gas was an argon-helium mixture $(72 \% \mathrm{Ar}+28 \% \mathrm{He})$ at $130 \mathrm{~Pa}$ filling pressure in a flowing regime. Spectroscopic observation of isolated spectral lines were made end-on along the axis of the discharge tube. A capacitor of $14 \mu \mathrm{F}$ was charged up to $2.5 \mathrm{kV}$. The line profiles were recorded using a shot-by-shot technique with a photomultiplier (EMI 9789 QB) and a grating spectrograph (Zeiss PGS-2, reciprocal linear dispersion $0.73 \mathrm{~nm} / \mathrm{mm}$ in the first order) system. The instrumental FWHM of $0.008 \mathrm{~nm}$ was determined by using the narrow spectral lines emitted by the hollow cathode discharge. The recorded profiles of these lines are Gaussian in shape within $8 \%$ accuracy in the range of the investigated spectral line wavelengths. The exit slit $(10 \mu \mathrm{m})$ of the spectrograph with the calibrated photomultiplier was micrometrically traversed along the spectral plane in small wavelength steps $(0.0073 \mathrm{~nm})$. The averaged photomultiplier signal (five shots at each position) was digitized using an oscilloscope, interfaced to a computer. A sample spectrum is shown in Fig. 1.

Plasma reproducibility was monitored by the Ar III and Ar IV lines and, also, by the discharge current (it was found to be within $\pm 4 \%$ ). Discharge characteristics were determined by analyzing the Rogowski coil signal. The values found were: discharge current $=6.1 \mathrm{kA}$, discharge period $=70 \mu \mathrm{s}$, thermal resistance $=0.27 \Omega$ and inductivity $=23 \mu \mathrm{H}$. A typical Rogowski coil signal is presented in Fig. 2. On the same figure the temporal evolution of the maximal intensity averaged over the 18 Ar IV spectral lines is also presented. It has a maximum at the 15 th $\mu \mathrm{s}$ after the beginning of the discharge when the profiles were analyzed. The relaxation time of the decaying plasma was $20 \mu \mathrm{s}$. 


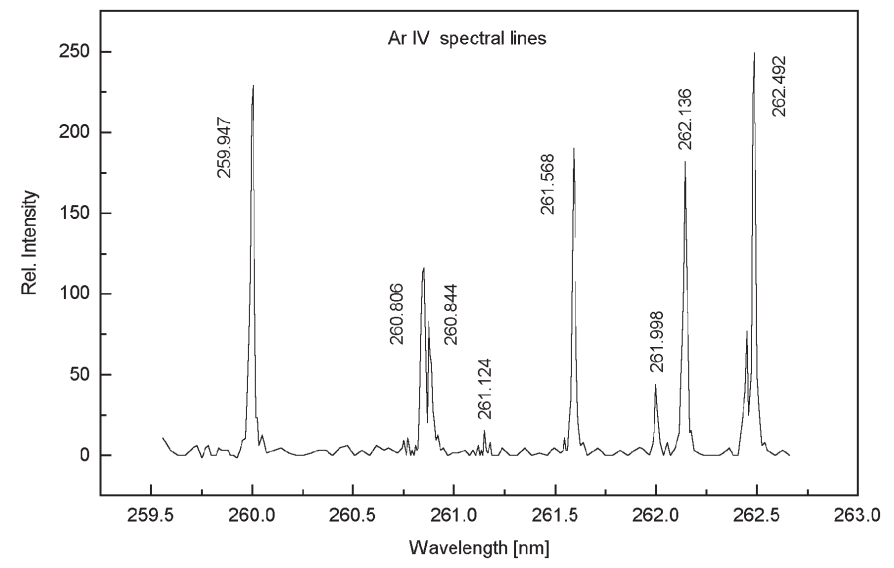

Fig. 1. Recorded Ar IV spectrum at the 15-th $\mu$ s after the beginning of the discharge

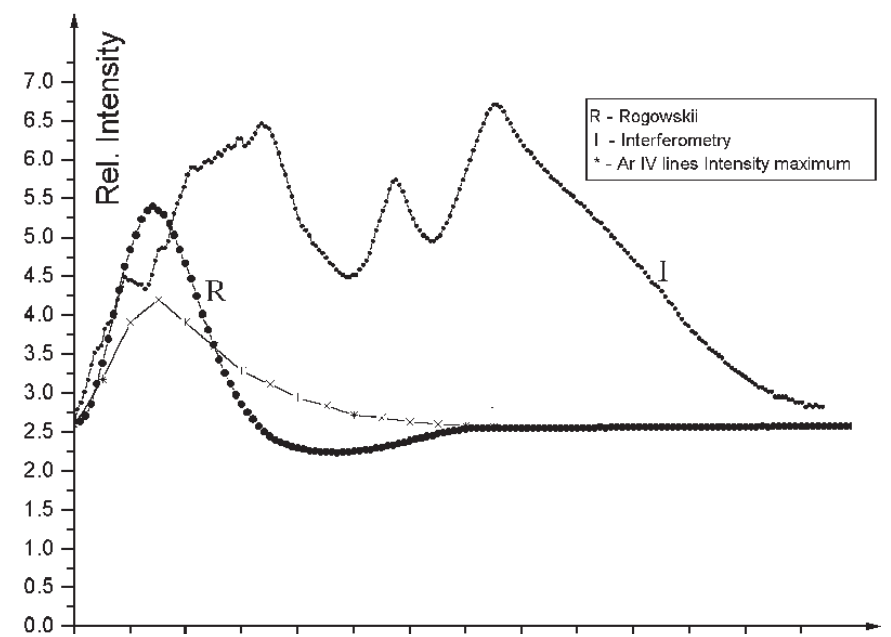

Fig. 2. Temporal evolution of the Rogowski coil (R) and interferometry (I) signal such as a line intensity maximum $\left(^{*}\right)$

The measured profiles were of the Voigt type due to the convolution of the Lorentzian Stark and the Gaussian profiles from Doppler and instrumental broadening. For the electron density and temperature in our experiments the Lorentzian fraction was dominant (over 80\%). Van der Waals and resonance broadening were estimated to be smaller by more than one order of magnitude in comparison to Stark, Doppler and instrumental broadening. The standard deconvolution procedure (Davies \& Vaughan 1963) was computerized using the least square algorithm. The Stark widths were measured with $\pm 15 \%$ error. Great care was taken to minimize the influence of self-absorption on Stark width determinations. The opacity was checked by measuring relative line intensity ratios within multiplet 4UV in Ar IV spectrum during plasma decay (280.94 nm and $278.89 \mathrm{~nm}$ ). The values obtained were compared with calculated ratios of the products of the spontaneous emission probabilities and the corresponding statistical weights of the upper levels of the lines. The necessary atomic data were taken from Wiese et al. (1969). It turns out that these ratios differed by less than $\pm 2 \%$ (across a wide range of the decaying plasma, see Fig. 3) testifying the absence of

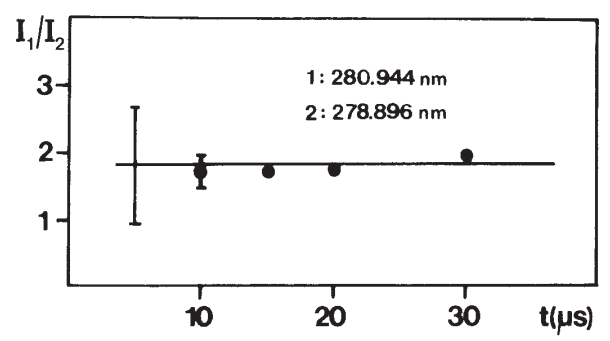

Fig. 3. Intensity ratio of two Ar IV lines (280.944 $\mathrm{nm}$ and $278.896 \mathrm{~nm}$ ) belonging to the low-lying $4 \mathrm{UV}$ multiplet during the plasma decay. - theoretical predictions (Wiese et al. 1969) within $\pm 50 \%$ uncertainties and $\bullet$, our measured values with $\pm 12 \%$ accuracy

self-absorption. In the 15 th $\mu$ s after the beginnig of the discharge (moment when the profiles were recorded) the experimental ratio $I_{1} / I_{2}$ is only $2 \%$ lower than the theoretical prediction.

The Stark shifts were measured relative to the unshifted spectral lines emitted by the same plasma (Purić \& Konjević 1972). The Stark shift of spectral lines can be measured experimentally by evaluating the position of the spectral line center recorded at two different electron density values during the plasma decay. In principle, the method requires recording of the spectral line profile at the high electron density $\left(N_{1}\right)$ that causes an appreciable shift and then later when the electron concentration has dropped to the value $\left(N_{2}\right)$ lower for at least an order of magnitude. The difference in the line center positions in these two cases is $\Delta d$, so that the shift $d_{1}$ at the higher electron density $N_{1}$ is:

$d_{1}=N_{1} \times \Delta d /\left(N_{1}-N_{2}\right)$.

The Stark shift data were corrected for the electron temperature decay (Popović et al. 1992). Stark shift data are determined with $\pm 0.0008 \mathrm{~nm}$ error at a given $N$ and $T$. The plasma parameters were determined using standard diagnostic methods (Rompe \& Steenbeck 1967). Thus, the electron temperature was determined from the Boltzmanslope on seven Ar III lines (330.2; 331.1; 335.8; 334.5; 333.6 ; 248.9 and $250.4 \mathrm{~nm}$ ) with a corresponding upperlevel energy interval of $8.32 \mathrm{eV}$, with an estimated error of $\pm 10 \%$, assuming the existence of LTE, according to criterion from Griem (1974). All necessary atomic data were taken from Wiese et al. (1969), NIST-database (2000), Kurucz (2000), Djeniže \& Bukvić (2001) and Striganov \& Sventickii (1966). The form of the electron temperature decay is presented in Fig. 4. The electron density decay was measured using a well known single laser interferometry (Ashby et al. 1965) technique for the $632.8 \mathrm{~nm} \mathrm{He}-\mathrm{Ne}$ laser wavelength with an estimated error of $\pm 7 \%$ and, also, by measurements of the convenient He II $\mathrm{P}_{\alpha}(468.57 \mathrm{~nm})$ Stark width. Temporal evolution of the typical interferometry signal is presented in Fig. 2. The electron density decay is presented, also, in Fig. 4.

$15 \mu \mathrm{s}$ after the beginning of the discharge, when the Ar IV spectral line profiles were analyzed, the electron 


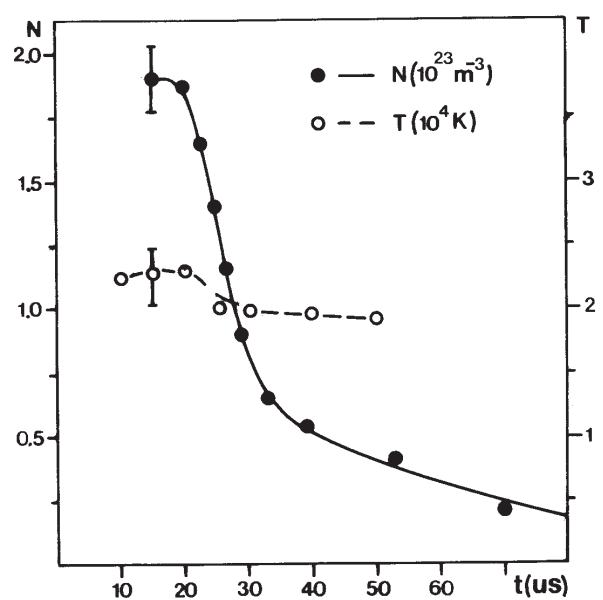

Fig. 4. Temporal evolution of the electron temperature $(T)$ and electron density $(N)$ during the plasma decay

Table 1. Measured Stark FWHM $\left(W_{\mathrm{m}}\right)$ and shift $\left(d_{\mathrm{m}}\right)$ values at an observed electron temperature $(T=22500 \mathrm{~K})$ and density $\left(N=1.910^{23} \mathrm{~m}^{-3}\right)$. Positive shift is toward the red

\begin{tabular}{|c|c|c|c|c|}
\hline Transit. & Multipl. & $\lambda(\mathrm{nm})$ & $W_{\mathrm{m}}(\mathrm{nm})$ & $d_{\mathrm{m}}(\mathrm{nm})$ \\
\hline \multirow{13}{*}{$4 s-4 p$} & ${ }^{4} \mathrm{P}-{ }^{4} \mathrm{D}^{0}$ & 283.025 & 0.0180 & 0.00 \\
\hline & $(4 U V)$ & 280.944 & 0.0210 & 0.00 \\
\hline & & 278.896 & 0.0190 & 0.0033 \\
\hline & & 277.626 & 0.0180 & 0.0032 \\
\hline & ${ }^{4} \mathrm{P}-{ }^{4} \mathrm{P}^{0}$ & 264.034 & 0.0160 & 0.0028 \\
\hline & $(5 \mathrm{UV})$ & 261.568 & 0.0165 & 0.00 \\
\hline & & 260.806 & 0.0185 & 0.0036 \\
\hline & ${ }^{4} \mathrm{P}-{ }^{4} \mathrm{~S}^{0}$ & 251.328 & 0.0165 & 0.00 \\
\hline & ${ }^{2} \mathrm{P}-{ }^{2} \mathrm{D}^{0}$ & 292.633 & 0.0210 & 0.0024 \\
\hline & (2) & & & \\
\hline & ${ }^{2} \mathrm{P}-{ }^{2} \mathrm{P}$ & 260.844 & 0.0215 & 0.00 \\
\hline & ${ }^{2} \mathrm{P} \_{ }^{2} \mathrm{P}^{0}$ & 259.947 & 0.0165 & 0.00 \\
\hline & & 252.569 & 0.0175 & 0.00 \\
\hline \multirow[t]{6}{*}{$4 s^{\prime}-4 p^{\prime}$} & ${ }^{2} \mathrm{D}-{ }^{2} \mathrm{~F}^{0}$ & 278.447 & 0.0190 & 0.0018 \\
\hline & (6UV) & 275.792 & 0.0200 & 0.0025 \\
\hline & ${ }^{2} \mathrm{D}-{ }^{2} \mathrm{D}^{0}$ & 262.492 & 0.0160 & -0.0013 \\
\hline & & 262.136 & 0.0190 & 0.003 \\
\hline & & 261.998 & 0.0160 & 0.003 \\
\hline & unidentif. & 400.51 & 0.0260 & \\
\hline
\end{tabular}

temperature was found to be $22500 \mathrm{~K} \pm 10 \%$ and the electron density was $1.9010^{23} \mathrm{~m}^{-3} \pm 7 \%$.

\section{Results}

The results of the measured Stark FWHM $\left(W_{\mathrm{m}}\right)$ and shift $\left(d_{\mathrm{m}}\right)$ values at $T=22500 \mathrm{~K}$ electron temperature and $N=1.910^{23} \mathrm{~m}^{-3}$ electron density are shown in Table 1.

\section{Discussion}

In order to compare existing experimental and theoretical Stark width values, their dependence on the electron temperature is given in Fig. 5. Theoretical $W$ values $(\mathrm{G}$, GM, SEM, SE) are calculated on the basis of various approximations, initiated by Dimitrijević \& Konjević (1981). Thus, SE and SEM denote the results of semiempirical and modified semiempirical predictions using Eqs. (4, 5) and Eqs. (7-10), respectively, from Dimitrijević \& Konjević (1981). G and GM denote $W$ values obtained on the basis of the semiclassical approximation (Griem 1974 and references therein) with 1.4 instead of $5-(4.5 / z)$ on the righthand side of Eq. (12) in Dimitrijević \& Konjević (1980) for the GM values. Mentioned calculations are performed only for four multiplets. In Hey et al. (1990), theoretical Stark width values, calculated on the basis of the impact and classical-path approximations (Hey \& Breger 1982), are also presented, but only for the plasma parameters observed in experiments: Platiša et al. (1975), Purić et al. (1988) and Hey et al. (1990). On the basis of our measured $W_{\mathrm{m}}$ and other experimental and theoretical values from Table 1 and Fig. 5, we can conclude that, in general, our new $W$ data agree well with theoretical predictions, $W_{\mathrm{G}}$, based on the semiclassical approximation for all four multiplets (4UV, 5UV, 6UV and 2). The agreement between values $W_{\mathrm{m}}$ and $W_{\mathrm{SEM}}$ is satisfactory (up to $25 \%$ accuracy). Experimental values from Purić et al. (1988) and Kobilarov \& Konjević (1990) show similar behaviour. On the other hand, Hey's et al. (1990) experimental Stark width values lie above all theoretical predictions. Theoretical values $W_{\mathrm{GM}}$ and $W_{\mathrm{SE}}$ lie below our experimental data and show agreement only with the first experimental $W$ data (Platiša et al. 1975) on about $21000 \mathrm{~K}$ electron temperature. So, the $W_{\mathrm{SE}}$ values lie about $50 \%$ lower than our data (on average). In general, at a $22500 \mathrm{~K}$ electron temperature, our $W$ data confirm the predictions based on the semiclassical theory $(G)$ and, also, the results of Hey's calculations (1990) within uncertainties of theory and of experimental accuracy.

In the case of the Stark shift, the situation is much different. Only one experiment (Kobilarov \& Konjević 1990) deals with the Ar IV d values. So, these measured and calculated (SEM) values have negative sign in the case of the 278.89, 280.94, 283.03 and $275.79 \mathrm{~nm}$ lines while we have measured very small, but positive shift values, or values equal to zero (see Table 1 ) with $\pm 0.0008 \mathrm{~nm}$ accuracy. The exception is $262.649 \mathrm{~nm}$ line which shows negative $d_{\mathrm{m}}$ value.

\section{Conclusion}

Taking into account agreement between this report and existing experimental and calculated Stark width values for $264.03 \mathrm{~nm}$ and $275.74 \mathrm{~nm}$ Ar IV spectral lines, one can recommend these lines as a reliable plasma diagnostic. These are predicted by the semiclassical theory $(G)$ (Griem 1974; Dimitrijević \& Konjević 1981) in a wide 


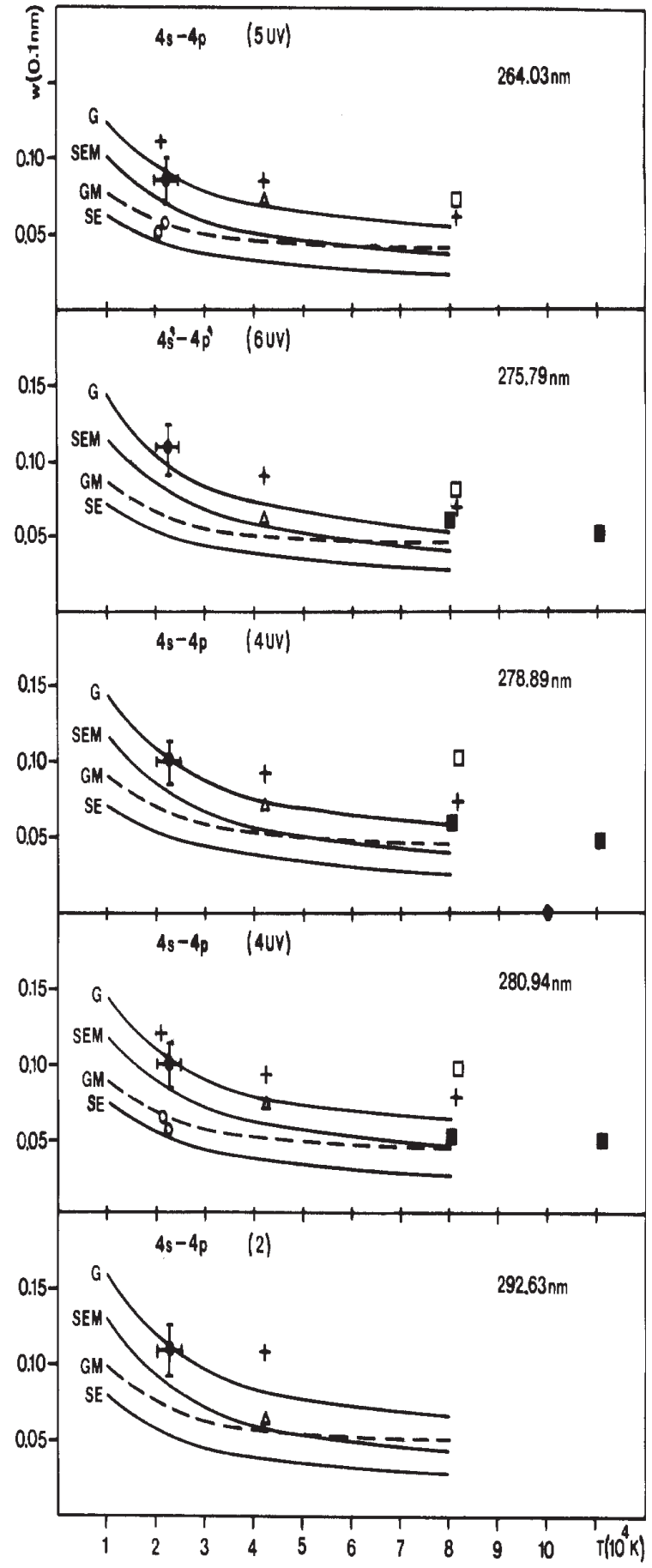

Fig. 5. Stark FWHM $(W)$ dependence on the electron temperature for the most investigated Ar IV lines belonging to the $4 \mathrm{~s}-4 \mathrm{p}$ and $4 \mathrm{~s}^{\prime}-4 \mathrm{p}^{\prime}$ transitions at an $10^{23} \mathrm{~m}^{-3}$ electron density. $\bullet$, our experimental results and those of other authors: $\circ$, Platiša et al. (1975); $\triangle$, Purić et al. (1988); $\square$, Hey et al. (1990) and $\boldsymbol{\square}$, Kobilarov \& Konjević (1990). G and GM denote values obtained on the basis of the semiclassical (Griem 1974) approximation, both SEM and SE denote values obtained on the basis of the modified semiempirical and semiempirical approximations, respectively. All these calculations were performed by Dimitrijević \& Konjević (1981). +, theoretical predictions by Hey et al. (1990) calculated at plasma parameters obtained by Platiša et al. (1975), Purić et al. (1988) and Hey et al. (1990). Error bars represent the width, electron density and electron temperature uncertanties range of the electron temperatures between $20000 \mathrm{~K}$ and $80000 \mathrm{~K}$, within $20 \%$ accuracy. Our measured Stark shift values have positive sign, contrary to the measured and calculated data using the modified semiempirical (SEM) theory (Kobilarov \& Konjević 1990). These discrepancies can be explained taking into account sensitivity of the shift calculations on the used atomic data. Namely, the number of perturbing levels which are included in the calculation has appreciable influence on the resulting shift (Hey \& Breger 1980). If one omits some of them, or if some levels are not known, erroneous results may appear. In this view, new calculations of the Ar IV Stark shifts would be helpful taking into account new atomic data (Zeippen 1995 and references therein).

\section{References}

Ashby, D. E. T. F, Jephcott, D. F., Malein, A., \& Raynor, A. 1965, Appl. Phys., 36, 29

Davies, J. T., \& Vaughan, J. M. 1963, ApJ, 137, 1302

Dimitrijević, M. S., \& Konjević, N. 1980, JQSRT, 24, 451

Dimitrijević, M. S., \& Konjević, N. 1981, Spectral Line Shapes, ed. B. Wende (de Gruyter, Berlin), 211

Djeniže, S., Srećković, A., Labat, J., Konjević, R., \& Popović, L. C. 1991, Phys. Rev. A., 44, 410

Djeniže, S., Milosavljević, V., \& Srećković, A. 1998, JQSRT, 59,71

Djeniže, S., \& Bukvić, S. 2001, A\&A 365, 252

Griem, H. R. 1974, Spectral Line Broadening by Plasmas (Acad. Press, New York)

Hey, J. D., \& Breger, P. 1980, JQSRT, 23, 311

Hey, J. D., \& Breger, P. 1982, S. Afr. J. Phys., 5, 11

Hey, J. D., Gawron, A., Xu, X. J., Breger, P., \& Kunze, H. J. 1990, J. Phys. B, 22, 241

Inglesias, C. A., Rogers, F. J., \& Wilson, B. G. 1990, ApJ, 360, 221

Kobilarov, R., \& Konjević, N. 1990, Phys. Rev. A, 41, 6023

Kurucz, R. L. 2000, Harward-Smitshonian Center for Astrophysics, CD-Rom 23

Lesage, A., \& Fuhr, J. 1998, Bibliography on Atomic Line Shapes and Shifts, Supp. 5 (April 1992 through December 1997), Publication de l'Observatoire de Paris

NIST- Atomic Spectra Database Lines Data (Wavelengths ordered)

Platiša, M., Popović, M., Dimitrijević, M. S., \& Konjević, N. 1975, Z. Naturforschung, 30a, 212

Popović, L. Č., Srećković, A., \& Djeniže, S. 1992, Proc. the 11th ICSLS, A25, Carry le Rouet, France

Purić, J., \& Konjević, N. 1972, Z. Phys., 249, 440

Purić, J., Djeniže, S., Srećković, A., et al. 1988, Z. Phys. D, 8, 343

Rompe, R., \& Steenbeck, M. 1967, Ergebnisse der Plasmaphysik und der Gaselektronik, Band 1 (Akademie Verlag, Berlin)

Striganov, R. A., \& Sventickii, N. S. 1966, Tablici Spectralnjih Linii (in Russian), Atomizdat, Moscow

Wiese, W. L., Smith, M. W., \& Miles, B. M. 1969, Atomic Transition Probabilities, vol. II NSRDS-NBS 22 (V.S. Government Printig Office, Washington)

Zeippen, C. J. 1995, Phys. Scr., 58, 43 